\title{
Looking ahead: Subjective time perception and individual discounting
}

\section{W. David Bradford ${ }^{1} \cdot$ Paul Dolan $^{2} \cdot$ Matteo M. Galizzi ${ }^{3}$}

Published online: 30 March 2019

(C) The Author(s) 2019

\begin{abstract}
We disentangle hyperbolic discounting from subjective time perception using experimental data from incentive-compatible tests to measure time preferences, and a set of experimental tasks to measure time perception. Two behavioral parameters are related to two factors affecting how we look ahead to future events. The first is some component of time preferences reflecting hyperbolic discounting. The second factor is that non-constant discounting may also be a reflection of subjective time perception: if people's perception of time follows a near logarithmic process (as heat, sound, and light do) then estimates of individual discounting will be mis-measured and incorrectly suggest hyperbolic discounting even if discounting over subjective time is constant. We empirically estimate the two distinct behavioral parameters using data collected from 178 participants in a lab experiment. The results support the hypothesis that apparent non-constant discounting is largely a reflection of non-linear subjective time perception.
\end{abstract}

Keywords Time preferences · Time perception · Hyperbolic discounting · Quasihyperbolic discounting

JEL Classifications D1 · D10 · D91

Electronic supplementary material The online version of this article (https://doi.org/10.1007/s11166-01909298-1) contains supplementary material, which is available to authorized users.

\author{
Matteo M. Galizzi \\ m.m.galizzi@1se.ac.uk \\ W. David Bradford \\ bradfowd@uga.edu \\ Paul Dolan \\ p.h.dolan@1se.ac.uk
}

Extended author information available on the last page of the article 


\section{Introduction}

Time discounting is considered a fundamental characteristic of human decision-making (Frederick et al. 2002). For example, individuals with higher discount rates may be less willing to invest in painful activities in the present even if such investments yield substantial benefits in the future (Barsky et al. 1997; Chapman and Coups 1999; Chabris et al. 2008; Bradford 2010; Sutter et al. 2013).

Multiple empirical methods have been developed over the past decades to estimate individual levels of discounting, ranging from survey questions involving hypothetical payouts (Dolan and Gudex 1995; Van der Pol and Cairns 2001), to laboratory or field experiments using incentive-compatible methods (Coller and Williams 1999; Harrison et al. 2002; Andersen et al. 2008, 2014; Epper et al. 2011; Andreoni and Sprenger 2012; Laury et al. 2012; Attema et al. 2016).

Perhaps the most widely debated finding in the literature is that individuals do not appear to always discount the future at a constant rate: discount rates tend to be higher for more proximate time periods and lower for more distal ones (Thaler 1981; Kirby and Marakovic 1995; Coller et al. 2012). This phenomenon has been typically explained in terms of hyperbolic or quasi-hyperbolic time discounting (Loewenstein and Prelec 1992; Laibson 1997).

Several alternative accounts have been proposed to explain non-constant discounting (Holden and Quiggin 2017). Ainslie (1975) relates it to individual impulsivity, whereas Loewenstein (1996) to the tempting influence and temporal proximity of "visceral factors" such as hunger, sexual arousal, cravings, and physical pain. Trope and Liberman $(2003,2010)$ point to different representations of near and distant future events in terms of cognitive concreteness. Others argue that declining discounting rates could also be due to "sub-additive discounting": the fact that the overall time horizon is partitioned into subintervals can increase the salience of the partitioned time components, and lead to higher discounting (Read 2001; Scholten and Read 2006). Prelec and Loewenstein (1991) and Frederick et al. (2002) observe that, as future payouts are inextricably associated with uncertainty, our valuation of inter-temporal tradeoffs not only depends on our "pure" time preferences, but also on perceived risks associated with the delay (Chesson and Viscusi 2000; Andersen et al. 2008; Coble and Lusk 2010). Epper et al. (2011) find that hyperbolic discounting is significantly associated with non-linear probability weighting in the subjective perception of probabilities ("sub-proportionality").

The presence of hyperbolic and quasi-hyperbolic discounting, moreover, is not ubiquitous in the literature. Andersen et al. (2008, 2014) elicit and jointly estimate risk and time preferences for representative samples of the Danish population and find clear evidence of constant discounting. Also Andreoni and Sprenger (2012) find no evidence of present bias in their experiment. Negative evidence about hyperbolic or quasi-hyperbolic discounting has also been documented by Anderhub et al. (2001), Harrison et al. (2002), and Laury et al. (2012), among others. In a recent literature review, Andersen et al. (2014) notice that most incentive-compatible evidence of hyperbolic and quasi-hyperbolic discounting occurs in samples of college students, while there is little evidence from real money choices of adult respondents over typical horizons of months (Andersen et al. 2014). Attema et al. (2016) compare discounting measured by the conventional "utility method" with a new "direct method" which 
measures discounting directly without the need of measuring utility, and find that, while there is prevailing evidence of decreasing impatience using the utility method, there is only weak evidence of decreasing impatience using the direct method, which explains the poor performance of the hyperbolic discount function to explain their data. Attema et al. (2018) extend the "direct method" to compare discounting for money and health, and find that constant discounting fit the data better than hyperbolic discounting.

There is a separate branch of the literature that suggests that the observed behavior may be less based in inconsistencies in actual time preferences than in perceptions about time duration (Read 2001; Prelec 2004; Zauberman et al. 2009). In particular, there is evidence suggesting that human understanding of time- either retrospectively or projected forward in time - is not a linear mapping from calendar time: e.g., 2 years are subjectively perceived as less than twice as far away as 1 year (Hornik 1984; Kim and Zauberman 2009). That people would perceive time in this manner can be explained by appealing to what is known as the "Weber-Fechner law", a fundamental principle in the psychology of perception that - together with "Stevens' power law" (Stevens 1957) - has been widely documented for other neuro-physiological stimuli such as heat, sound, and light. If these psychophysics laws also hold for time perception, then calculations of the discount rates based on the assumption that perception of time duration is linear may be distorted.

In this paper, we simultaneously elicit and estimate respondents' subjective perception of time and implied discount rates. We innovatively build on the literature, and in particular on the method developed by Kim and Zauberman (2009) and Zauberman et al. (2009) to measure time perception, in four ways: i) we elicit time discounting using state-of-the-art experimental tests with real monetary rewards; ii) we consider different time intervals spanning from 1 day to 1 year to isolate "first period" effects and hyperbolic versus quasi-hyperbolic discounting; iii) we adjust for individual heterogeneity in the subjective time scales to draw cross-subjects comparisons; iv) we look at the links between retrospective and prospective perception of time.

We find that individuals do indeed compress future time perception in ways very reminiscent of the general Weber-Fechner and Stevens principles. Further, once that compression is taken into account, we find evidence that discount rates are higher for today versus later times, but essentially constant and statistically undistinguishable for all later times from 1 week onwards. While discounting rates based on "objective time" replicate the usual hyperbolic preferences, much of the hyperbolic pattern is absent in the curve of the discounting factors obtained from "subjective time", which closely resembles the shape of a quasi-hyperbolic function. Thus, we argue that there is good reason to suspect that considering direct measures of subjectively perceived time instead of objective time can lead to different conclusions on the estimated discount rates even when these are elicited through experimental tests with real monetary rewards.

The rest of the article is structured as follows. In Section 2 we review the background, the objectives, and the main features of our study, and its contributions to the literature. Section 3 describes the experiment, while in Section 4 we present the econometric model. Section 5 discusses the results, while in Section 6 we conclude by discussing some of the implications of our findings. 


\section{Background and contributions}

\subsection{The discounting function}

As reviewed by Frederick et al. (2002), the study of inter-temporal choice has a long tradition in the history of economics. It is useful to follow their conceptual distinction between "time discounting", which includes any reason for caring less about a future outcome, and "time preference", which refers, more specifically, to the "pure" preference for immediate over delayed utility. In the early economists' views, time discounting was thought of as an amalgamation of disparate psychological motives, which can explain why even now it overlaps with different concepts in psychology, such as lack of self-control and impulsiveness (Kirby et al. 1999).

The basic modern theoretical approach in economics, however, was introduced by Samuelson (1947). His discounted utility model assumes individuals select some level of consumption in each time period, $\mathrm{x}_{\mathrm{t}}$, subject to an income/wealth constraint, in order to maximize the present value of a stream of separate utilities, where future utilities were weighted less heavily compared to the current level of utility:

$$
U^{t}\left(x_{1}, \ldots, x_{T}\right)=\sum_{t=0}^{T} D(t) u\left(x_{t}\right)
$$

In Samuelson's model the weighting factor, $\mathrm{D}(\mathrm{t})$ is constant across all time periods, and corresponds to the "discount rate". In the exponential model, the discount function $\mathrm{D}(\mathrm{t})$ has the form:

$$
D^{E}(t)=\left(\frac{1}{1+\delta}\right)^{t}
$$

for $\mathrm{t} \geq 0$, and where the exponential discount rate $\mathrm{d}^{\mathrm{E}}(\mathrm{t})=\delta$ is constant over time which, coupled with an additively-separable inter-temporal utility function, implies timeconsistent preferences.

In the 1990s a body of psychometric and behavioral economics literature - based in part on work of Strotz (1955) - suggested the "constant discount rate" was unrealistic (Ainslie 1991; Loewenstein and Prelec 1992; Kirby and Marakovic 1995; Laibson 1997). In particular, in the hyperbolic formulation by Loewenstein and Prelec (1992), the discount function takes the form:

$$
D^{H L P}(t)=\left(\frac{1}{1+\alpha t}\right)^{\frac{\beta}{\alpha}}
$$

This implies that the rate of change in $\mathrm{D}(\mathrm{t})$ declines as $t$ increases - that is, that an individual's rate of discounting for consumption delayed until tomorrow is larger than the rate of discounting for consumption that must be delayed by a day 1 year from now. Behaviorally, this implies that people's preferences are time-inconsistent.

One key departure from the pure hyperbolic model is the quasi-hyperbolic discounting model developed by Phelps and Pollak (1968) in the context of a social 
planning problem and popularized in economics by Laibson (1997). In the quasihyperbolic model, the discount function is $\mathrm{D}^{\mathrm{QH}}(\mathrm{t})=1$ if $\mathrm{t}=0$ and:

$$
D^{Q H}(t)=\frac{\beta}{(1+\delta)^{t}}
$$

if $t>0$. The discount function mimics many of the traits of a hyperbolic discounting function (hence the "quasi-"), though this is driven entirely by the greater weight to "first period" utility compared with all other periods. In particular, when $\beta<1$ the discount rates decline over time accounting for a "present bias".

One aspect of this Strotz-Ainslie-Laibson quasi-hyperbolic discounting model that is relatively under-investigated in empirical applications is which "first" period is different from the subsequent periods (Ebert and Prelec 2007). A natural candidate for such "first" period is 1 day. A 1-day "first" period is consistent with the observation that periods of time beyond 1 day are treated as categorically different for biological reasons: the circadian clock, in fact, regulates basic aspects of human physiology and behavior, and is synchronized by the natural 24-hours periodicity of light (Wittmann and Paulus 2008).

\subsection{Accommodating non-linear subjective time in the discounting function}

A second aspect of interest arises from the difference between what people think when, in experiments, they are asked to compare today to 1 month and when they are asked to compare today to 3 months. It is natural to assume that the individuals will then consider tradeoffs across two periods, one of which is exactly three times as far away as the other. However, there is good reason to be cautious about this assumption.

Ernst Weber (1978) proposed in the early 1800s that people's senses do not function linearly. This idea, subsequently expanded by Gustav Fechner, has come to be seen as one of the basic principles of the psychology of perception. Essentially, the so-called "Weber-Fechner law" states that the minimum detectible difference between two levels of a stimulus is proportional to the percentage change in the input. Thus, the perceived difference, $d p$, between two stimuli, $S_{0}$ and $S$ (e.g., the intensity of heat) are:

$$
d p=k \frac{d S}{S}
$$

Integrating this relationship, solving for the constant of integration, and rearranging yields:

$$
p=k \ln \left(\frac{S}{S_{0}}\right)
$$

In other words, the perception of a stimulus is proportional to the log of the change in the actual stimulus.

A competing law in psychophysics is the so-called "Stevens' power law" that revises and corrects the Weber-Fechner law based on direct scaling of subjective magnitude. 
The Weber-Fechner and Stevens' power laws have been widely documented for a range of neuro-physiological perceptions, such as heat, sound, and light. Abstract constructs, such as numbers, appear to also induce logarithmic relationships between stimulus and perception, even among non-human subjects (Dehaene 2003). Thus, this non-linearity in subjective experiences relative to the objective stimulus appears universal and operating at a biological level.

More recently, evidence is growing that the Weber-Fechner and Stevens' power laws may be important also for human subjective perception of time (Read 2001; Wittmann and Paulus 2008; Zauberman et al. 2009). It can be shown, in fact, that the two psychophysics laws give rise to two major families of discounting functions. ${ }^{1}$

On the one hand, the Weber-Fechner law for subjective time perception can be written as

$$
f(t)=\left(\frac{1}{\alpha}\right) \ln (1+\alpha t)
$$

where $f(t)$ is the subjective perception of time $t$. The above parameterization is convenient because $f(t)$ becomes linear as $\alpha \rightarrow 0$, and is increasingly concave as $\alpha$ increases. If one substitutes the function $f(t)$ of subjective time perception in place of the objective time $t$ in the above standard exponential discounting function

$$
D^{E}(t)=\left(\frac{1}{1+\delta}\right)^{t}
$$

one can directly obtain the Loewenstein-Prelec formulation of the above hyperbolic discounting function $D^{H L P}(t)$ :

$$
D(t)=\left(\frac{1}{1+\delta}\right)^{f(t)}=\left(\frac{1}{1+\delta}\right)^{\left(\frac{1}{\alpha}\right) \ln (1+\alpha t)}=e^{-\beta f(t)}=e^{\left(-\frac{\beta}{\alpha}\right) \ln (1+\alpha t)}=(1+\alpha t)^{-\frac{\beta}{\alpha}}=\left(\frac{1}{1+\alpha t}\right)^{\frac{\beta}{\alpha}}
$$

where $\beta=\ln (1+\delta)$.

On the other hand, Stevens' power law for subjective time perception can be written as

$$
f(t)=t^{\alpha}
$$

where $f(t)$ is, again, the subjective perception of time $t$. If one substitutes subjective $f(t)$ in place of objective $t$ in the standard exponential discounting function, one can directly obtain a general formulation of an entire family of subjective time discounting specifications based on Stevens' power law:

$$
D(t)=\left(\frac{1}{1+\delta}\right)^{f(t)}=\left(\frac{1}{1+\delta}\right)^{t^{\alpha}}=e^{-\beta t^{\alpha}}
$$

where, again, $\beta=\ln (1+\delta)$.

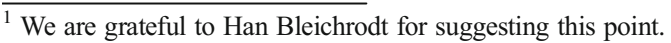


A specific discounting function within the above family has been proposed by Read (2001) precisely to incorporate a subjective perception of time, and has been later called the Weibull discounting function by Jamison and Jamison (2011) because it has an associated Weibull probability density function. The discount factor for this ReadWeibull discounting model is

$$
D^{W}(t)=e^{-\delta t\left(\frac{1}{\beta}\right)}
$$

for $\delta>0$ and $\beta>0$. When $\beta=1$ the Read-Weibull discounting function collapses to the exponential discounting model. The parameter $\beta$ in the function, in fact, governs the subjective perception of time, in the sense that it either "expands" or "contracts" time. In particular, when $\beta>1$ the individual perceives the time to "slow down" as if time has contracted, which yields declining discount rates. On the other hand, if $\beta<1$ the individual perceives the time to "speed up" as if time has expanded. ${ }^{2}$

\subsection{Eliciting discount rates and the implications of non-linear subjective time}

If subjective time indeed differs from objective time and the Weber-Fechner and Stevens' power laws do extend to how long people perceive time, this would represent a potential confounder in the empirical measurement of individual discount rates. For instance, when subjects in an experiment hear questions about getting something in 30 days vs. 90 days, they may be really making their choices using time frames of $f(30)$ and $f(90)$, where $f($.) reflects their subjective perception of how long 30 and 90 days are. It may well be the case that for some respondents $f(90)<3 * f(30)$, because they perceive more vividly the duration of the time periods which are closer to the present. If this is the case, then the estimates of individual discount rates using objective (rather than subjective) time could be mis-calculated.

In order to illustrate this point, consider the typical experimental task to measure time preferences. Coller and Williams' (1999) work appears to be the first example of an incentive-compatible study to elicit time preferences. Collier and Williams (1999) offered their subjects payouts of real money under controlled laboratory settings using a multiple price list (MPL) of binary options between a "Smaller Sooner" (SS) amount, and a "Larger Later" (LL) amount, and estimated rates in the $20 \%$ per year range. The MPL approach by Coller and Williams, and further developed by Harrison et al. (2002), has become the standard method to elicit time preferences with real monetary incentives. $^{3}$

While below we illustrate our point considering the MPL method, recently alternative procedures have been proposed to elicit time preferences, such as: the "converting delay into risk" method by Takeuchi (2011) that elicits both the equivalent probability

\footnotetext{
${ }^{2}$ Andersen, Harrison et al. (Andersen et al. 2014) review other formal specifications related to the ReadWeibull discounting function, such as: its general functional form due to Roelofsma (1996); the "Constant Sensitivity" (CS) power function proposed by Prelec (2004) and Ebert and Prelec (2007); the "Constant Relative Decreasing Impatience" function by Bleichrodt et al. (2009); the "unit invariance" discounting function used by Attema et al. (2016); and a variety of others..

${ }^{3}$ Moreover, when combined with analogous MPL tasks to elicit risk preferences, it allows us to conduct joint "structural" estimations of risk and time preferences considering a broad range of theoretical models (Andersen et al. 2008, 2014; Cheung 2015a, b).
} 
under risk and the equivalent delay over time that make a subject indifferent between a given pair of payoffs; the "convex time budget" method (CBT) by Andreoni and Sprenger (2012), where subjects are allowed to choose any convex combination of the SS and LL payments (see also the framework by Cubitt and Read 2007); the "binary lottery" method by Laury et al. (2012), where individual choices are over two payoff levels in which the probability of future payment is varied instead of its size; the "inter-temporal HL design for time" by Cheung (2015a, 2016) that transposes the wellknown Holt and Laury (2002) (HL) design to elicit risk preferences from state-payoff space into time-dated payoff space; and the already mentioned "direct method" by Attema et al. $(2012,2016,2018)$ which measures discounting without requiring any knowledge of utility, and which has been applied to measure discounting of discrete monetary outcomes, as well as of flow health variables such as quality of life (Attema et al. 2012, 2018). Recent comparisons of different experimental methods to measure time preferences could be found in Andreoni et al. (2015), Angerer et al. (2015), Cheung (2015a, 2016), and Attema et al. (2016).

Consider the typical methodology of the MPL experiments. Figure 1 is a reproduction of the table from Coller and Williams (1999) that contained their experimental test. Respondents were presented with options to choose between two different monetary payouts - either in 1 month (SS) or in 3 months (LL) — and asked to choose in each row the option that would be preferred. The logic of the method is that if a person has a personal discount rate of, say, 5.5\% per year, then they will prefer Option A (SS) for the first four rows of the experiment, and Option B (LL) for row five and every row thereafter. Thus, while the experimenter cannot know the discount rate is $5.5 \%$, she can know that it is bounded by $5.13 \%$ below and $7.79 \%$ above. After that, the econometric methods typically used are simple grouped or interval regression; ordered probit using the information on the upper and lower bounds; non-linear least squares; or "structural" estimation of the latent parameters in the utility functions using maximum-likelihood methods (Andersen et al. 2008).

A person will choose the SS payoff if the present value of that is higher than the present value of the LL payoff amount, given her discount rate. If we use the basic framework in Fig. 1, but assume Option A is for an immediate payout rather than 1 month away (which merely simplifies the illustration), then we know the respondent would choose Option A iff

$$
500>\frac{501.67}{(1+d)^{60 / 365}}
$$

where $d$ is the respondent's daily discount rate. Using this logic, the econometrician will infer that the lower bound can be calculated using the relationship

$$
d=\exp \left(\frac{\ln 501.67-\ln 500}{60 / 365}\right)-1
$$

Note that this calculation requires that the respondent is thinking "60 days" when making the implicit calculation that permits her to provide an answer to which option is preferred. 


\begin{tabular}{lcccccc}
\hline $\begin{array}{c}\text { Payoff } \\
\text { alternative }\end{array}$ & $\begin{array}{c}\text { Payment option A } \\
\text { (pays amount } \\
\text { below in 1 } \\
\text { month) }\end{array}$ & $\begin{array}{c}\text { Payment option B } \\
\text { (pays amount } \\
\text { below in 3 } \\
\text { months) }\end{array}$ & $\begin{array}{c}\text { Annual } \\
\text { interest } \\
\text { rate (AR) }\end{array}$ & $\begin{array}{c}\text { Annual } \\
\text { effective } \\
\text { interest rate } \\
\text { (AER) }\end{array}$ & $\begin{array}{c}\text { Preferred } \\
\text { payment } \\
\text { option (Circle } \\
\text { A or B) }\end{array}$ \\
\hline 1 & $\$ 500$ & $\$ 501.67$ & $2.00 \%$ & $2.02 \%$ & $\mathrm{~A}$ & $\mathrm{~B}$ \\
2 & $\$ 500$ & $\$ 502.51$ & $3.00 \%$ & $3.05 \%$ & $\mathrm{~A}$ & $\mathrm{~B}$ \\
3 & $\$ 500$ & $\$ 503.34$ & $4.00 \%$ & $4.08 \%$ & $\mathrm{~A}$ & $\mathrm{~B}$ \\
4 & $\$ 500$ & $\$ 504.18$ & $5.00 \%$ & $5.13 \%$ & $\mathrm{~A}$ & $\mathrm{~B}$ \\
5 & $\$ 500$ & $\$ 506.29$ & $7.50 \%$ & $7.79 \%$ & $\mathrm{~A}$ & $\mathrm{~B}$ \\
6 & $\$ 500$ & $\$ 508.40$ & $10.00 \%$ & $10.52 \%$ & $\mathrm{~A}$ & $\mathrm{~B}$ \\
7 & $\$ 500$ & $\$ 510.52$ & $12.50 \%$ & $13.31 \%$ & $\mathrm{~A}$ & $\mathrm{~B}$ \\
8 & $\$ 500$ & $\$ 512.65$ & $15.00 \%$ & $16.18 \%$ & $\mathrm{~A}$ & $\mathrm{~B}$ \\
9 & $\$ 500$ & $\$ 514.79$ & $17.50 \%$ & $19.12 \%$ & $\mathrm{~A}$ & $\mathrm{~B}$ \\
10 & $\$ 500$ & $\$ 516.94$ & $20.00 \%$ & $22.13 \%$ & $\mathrm{~A}$ & $\mathrm{~B}$ \\
11 & $\$ 500$ & $\$ 521.27$ & $25.00 \%$ & $28.39 \%$ & $\mathrm{~A}$ & $\mathrm{~B}$ \\
12 & $\$ 500$ & $\$ 530.02$ & $35.00 \%$ & $41.88 \%$ & $\mathrm{~A}$ & $\mathrm{~B}$ \\
13 & $\$ 500$ & $\$ 543.42$ & $50.00 \%$ & $64.81 \%$ & $\mathrm{~A}$ & $\mathrm{~B}$ \\
14 & $\$ 500$ & $\$ 566.50$ & $75.00 \%$ & $111.53 \%$ & $\mathrm{~A}$ & $\mathrm{~B}$ \\
15 & $\$ 500$ & $\$ 590.54$ & $100.00 \%$ & $171.45 \%$ & $\mathrm{~A}$ & $\mathrm{~B}$ \\
\hline
\end{tabular}

Fig. 1 Example of discounting elicitation test. (Coller and Williams 1999)

If, on the other hand, some version of the Weber-Fechner or Stevens' power laws is in play, the respondent does not actually think "60 days" when choosing options for the rows in Fig. 1. Rather, she is imagining her subjective perception of how long 60 days actually is: $f(60)$. Thus, the econometrician should be calculating the upper and lower bounds based on the subjective rather than objective time, using

$$
d=\exp \left(\frac{\ln 501.67-\ln 500}{f(60) / 365}\right)-1 .
$$

More generally, without reference to the specific values from Fig. 1, the lower bound for the daily discount rate should be calculated as

$$
d=\exp \left(\frac{\ln F V^{\min }-\ln P V}{f(t) / 365}\right)-1
$$

and not (11) - with the corresponding shift for the upper bound. Thus, the bounds using (11) may simply be mis-measured. In particular, if the function $f(\mathrm{t})$ is non-linear and reasonably logarithmic in shape, then this measurement error could produce estimated discount rates that appear hyperbolic-even when underlying time preferences for all periods other than the "first" period are actually constant. 


\subsection{What we contribute}

We assess individual subjective perception of time in a way that allows us to directly estimate the function $f(\mathrm{t})$ in Eq. (13) above, and so to correct the estimates of the bounds of each respondent's revealed discount rate for her individual perception of time.

We build on the method originally proposed by Kim and Zauberman (2009) and Zauberman et al. (2009) to measure subjective time perception. In a nutshell, the method proposed by Kim and Zauberman (2009) and Zauberman et al. (2009) asked subjects to imagine, for instance, "a day 3 months later", and presented them a slider task where the left-most end of the slider represented "very short" while the right-most of the line represented "very long". Participants were asked to place a mark on the slider to indicate how long they perceived the duration to be "between today and a day 3 months later", for instance.

We innovatively build on the method by Kim and Zauberman (2009) and Zauberman et al. (2009) in four ways. First, we combine their method with the estimation of individual discounting functions elicited through state-of-the-art experimental tests with real monetary rewards. Kim and Zauberman (2009) and Zauberman et al. (2009) do not in fact employ any incentive-compatible payments in the experimental tests to elicit time preferences, but instead rely on purely hypothetical questions on inter-temporal preferences.

Second, Zauberman et al. (2009) asked about durations of 3 months, 1 year, and 3 years (between-subjects experiment 1), or about durations from 3 months to 36 months in 3-month increments (within-subjects experiment 2). In contrast, we ask respondents about time intervals that span the range of a plausible 1-day "first period" effect, all the way through a time frame long enough to be near the point where discount rates stop falling under the hyperbolic preferences hypothesis. Thus, we ask respondents to evaluate time durations of 1 day, 1 week, 4 weeks, 13 weeks, 26 weeks, and 52 weeks. We also ask them to choose between SS and LL options over those same intervals using an overlapping design, so that we can plausibly evaluate hyperbolic versus quasi-hyperbolic behaviors.

Third, in Zauberman et al. (2009) within-subjects experiment 2 the responses to the subjective time perception task were all "transformed...into month units based on the mean value for the 3-month time horizon" (page 548) — not the individual value - so that the left end point of the horizontal line ("very short") essentially worked as a population average "anchor" or reference point. In contrast, we rescale the individual responses for the time perception of 1 week, 4, 13, 26, and 52 weeks using the same subject perception of 1 day, so that individual heterogeneity in the implied subjective time scales is normalized out, permitting straightforward crossperson comparisons.

Fourth, while Kim and Zauberman (2009) and Zauberman et al. (2009) only focused on prospective perception of time, we introduce a measure of retrospective recall time dilation over the short term. In our experiment, respondents sat in their lab cubicles in a basement room without windows or clocks, and all watches and cell phones were taken prior to entry in the lab. Thus, participants had no objective (external) means of knowing what time it was. Twice during the experiment and at the end, respondents were asked how many minutes they thought had passed since the experiment began. This design feature allows us to test the conjecture that the subjects who compressed 
time retrospectively were also more likely to compress their time prospectively. Moreover, there seems to be little reason to expect that this retrospective time compression would be a direct predictor of discount rate for a given subjective time frame once the compression is taken into account. Thus, we use the measure of bias in estimating recent time as an instrument in our econometric model.

\section{The experiment}

We recruited subjects to participate in experiments at the LSE Behavioural Research Lab (BRL) in the summer of 2011. All subjects were recruited from volunteers within the BRL mailing list (about 5000 subjects), which includes current undergraduate and post-graduate students of LSE and other institutions within the University of London, former students, members of staff, and non-student subjects. A total of 178 subjects, from different backgrounds, participated in the experiment and signed up in of one the 18 experimental sessions, all run at the BRL. There were no other eligibility or exclusion criteria to select participants. In the email invitation, subjects were not informed about the exact nature of the experiment that would be conducted, and were only told that: the experiment would last about an hour; they would receive $£ 10$ for their participation; they would have the chance to get an extra payment related to their tasks. Subjects could sign up for any of four one-hour sessions taking place between 11 am and $3 \mathrm{pm}$ at every working day of the week. The experiment received full approval from the LSE Research Ethics Committee.

Participants were brought into the BRL lab in small groups. Upon arrival at the lab, subjects received an anonymous four-digit ID code assigned by the online recruitment system (SONA), read and signed an informed consent form, and were randomly assigned to a corresponding desk. Subjects were asked to wear a sticker tag with their ID code, as well as their assigned desk for the duration of the experiment. Also, as mentioned, all timepieces and cell phones were taken from participants before entering the lab and kept in a safe room during the entire experiment. The lab is in the basement of a building at LSE with florescent lighting, no windows and no clocks, and has individual cubicles divided by large partitions to prevent visual contact between subjects. In the lab, respondents were not given access to the internet at their desks, and they were given verbal and written instructions on paper forms.

The experiment progressed in three phases. Subjects were given specific instructions at the beginning of each phase and answered each of the three phases separately. Phase 1 consisted of gathering responses to a comprehensive questionnaire on socioeconomic and health characteristics, subjective well-being questions, as well as questions about the subjective belief about how far away various durations of time seemed in the future.

In particular, the subjective time questions involved asking respondents to imagine, for instance, "a day four weeks from now". Subjects were presented a slider task and told that in the line presented below, the left-most end of the line represented "very short" while the right-most of the line represented "very long". Participants were then asked to place a mark on the line to indicate how long they perceived the duration to be "between now and 1 day four weeks from now". The time frames asked were: tomorrow, 1 week, 4 weeks, 13 weeks, 26 weeks, and 52 weeks. (See Appendix A 
for a sample question.) Each question was presented separately and the order of the different time frames was randomly assigned (beginning with the 4-weeks time frame question). The text of the question explicitly instructed the participants to consider where they would place the mark carefully and that they could not change their choice.

In Phase 2, as well as at several points in time during the sessions, subjects were also asked how much time they thought to have passed from the beginning of the experiment.

During Phase 3 of the experiment subjects made binary choices (108 in total) of when they would like to receive real monetary amounts over the same time frames over which the earlier subjective time perception questions were asked. In particular, following Harrison et al. (2002) and Andersen et al. (2008), we used a sequence of questions within a multiple price list (MPL) test to elicit time preferences. In each question, subjects were asked to choose between two paired options. Option A (the SS option) gave a "principal" amount $X$ in a "sooner" period of time $t$. This was either the same day, or the day immediately following the day, of the experiment (see below). On the other hand, Option B (the LL option) gave a monetary amount $X+Y$ in a future period of time $t+T$, with $T$ corresponding to each of the specific time frames used in the subjective time perception test, namely 1 day, 1 week, 4 weeks, 13 weeks, 26 weeks, and 52 weeks from the "sooner" period of time. We chose the "principal" amount of money $X$ to be equal to $£ 100$, a relatively large nominal value that helps i) make salient the perceived differences in the LL payments even for short time horizons; and ii) mitigate distortions due to subjects possibly rounding the delayed payments up to the nearest dollar. The amounts of money $Y$ were chosen in a way that a subject switching from option A to option B would reveal the upper and lower bounds of her implicit discount for the time interval $T$. In particular, monetary amounts $Y$ in each time frame were chosen in a way to associate each pair of options to a minimum implicit annual discount rate-assuming objective time perception-of 5, 10, $20,30,40,50,60,70,80 \%$, respectively. Amounts for the LL monetary values were calculated using simple-rather than compounded (e.g. quarterly) —annualized discounting rates. This was done to ensure consistency with the standard practices and current regulations within the banking and financial sectors in the UK where, typically, interest rates for mortgages, bonds, and credit cards are always expressed as simple annualized rates.

There were thus nine SS-LL paired options questions for each of the six time frames corresponding to the ones used in the subjective time perception test. For all subjects, each of these 54 questions was repeated: half of the 108 questions referred to "now" as the time in the SS option, while half of them referred to "tomorrow" as the sooner date. That is, in the 54 "front-end delay" (FED) choices (Coller and Williams 1999), both the SS and the LL rewards were shifted forward by 1 day. Including questions both with and without FED allows us to capture genuine occurrence of non-constant discounting rates: by exclusively using FED choices, in fact, one may incorrectly infer exponential discounting simply because the questions' design is unable to record nonconstant discount rates occurring within the FED horizon (Andersen et al. 2014). 
The MPL test presented to subjects the different SS-LL pairs of options and the delay frames in a "broken" sequence and a randomly presented order. This was done in order to ensure coherence with the subjective time questions, which were also presented in random order, and to avoid forcing "consistency" in individual responses to the MPL time preferences questions. ${ }^{4}$ When choosing between Option A (SS) and Option B (LL) in a series of MPL questions with the usual presentation as in Fig. 1 subjects may realize that, once they switch from Option A to Option B, it would be inconsistent to "switch back" to Option A in the subsequent questions. That is, one may wonder if the series of binary choices framed in an unbroken ascending order of implicit discounting rates may in principle impose consistency in choices where there is little in reality. To give subjects an opportunity to make "inconsistent" choices and to assess the extent to which respondents make genuinely consistent choices, we thus broke our six discounting choice tables into individual rows, and presented all the choices in random order, alternating pairs differing both for time delays and implicit discounting rates, so that as they answer the question respondents would be unable to detect whether they were being consistent or not.

Crucially, subjects were told in advance that their answers to the questions in the MPL tests were going to determine their final payments for the experiment. Respondents were informed in advance that, at the end of the experiment, one of the 108 pairs of options for the time preferences would be randomly selected to be used for real for the final payment; and that, for each set of choices, each participant in the session had a $5 \%$ chance to be randomly selected to actually receive the payout corresponding to the option that she would prefer within the randomly selected pair.

To maximize the transparency and credibility of the payment procedure, all random selections took place physically in a room next to the lab in front of all subjects: they consisted in the draw of a ball from a bag containing either 108 numbered ping pong balls, to select the pair of options relevant for the payment, and then in the draw of a ball from a bag containing 20 balls, one for each desk in the lab, to determine whether each participant received the payment or not. To ensure that subjects were able to perfectly recall and check their preferred choices in the selected pairs, participants retained the handbook with their actual answers during the whole random selections procedure (and of course could always check their assigned desk from the sticker tag).

Another key concern in time preferences experiments is to ensure that transaction costs and credibility of payments are the same across options at sooner and later dates (Andreoni and Sprenger 2012; Cheung 2015a, b. To achieve this, all payments for the time preferences questions were paid out using checks not payable before the due date, so that every subject selected for the payment had to make a trip to the bank to collect her earnings, regardless of the payment date. To maximize the credibility of the payments, each check (from the largest bank in the UK) was signed by the experimenter in front of

\footnotetext{
${ }^{4}$ Frederick et al. (2002), for instance, have discussed an "anchoring" effect potentially occurring when respondents are asked to make a sequence of choices between a SS and a LL reward, with the first faced choice biasing subsequent choices. Andersen et al. (2014) have explored the effect of presenting subjects with time preferences questions in either an ascending or a descending order of time horizons (i.e. from 2 weeks to 12 months, or the other way around), and found that using ascending time horizons leads to a decrease of about $2.3 \%$ in the implicit discounting rates. In both their treatments, however, within each time horizon block, the list of time preferences questions were presented in an unbroken increasing order of the amounts of money paid in the LL option, that is, in an ascending order of implicit discounting rates.
} 
the subjects, and secured by a stamp with the recognized logo of the LSE BRL. A registry of all present and future due payments was also signed by both the experimenter and each selected subject under an official LSE letterhead. The $£ 10$ fixed show-up fees were all paid in cash at the end of each session. In the instructions, participants were made aware of all these details prior to their choices. As directly confirmed by our banking records, all subjects cashed in their checks at their due dates.

In addition to the 108 time preferences questions, subjects in our experiment also answered 3 sets of 10 binary lottery questions each, in order to elicit their risk preferences using the HL method. In particular, looking at a subject's switching point between the "safer" and the "riskier" lottery in the binary lottery questions, and under the assumption of constant relative risk aversion (CRRA), we calculate the midpoint of the range of CRRA values associated with that switching point, and we use it as a control in the estimations of the subjective perception of time and of the discount rates. ${ }^{5}$

\section{Econometric model}

Assume that each respondent can be characterized by two latent variables: the subjective perception of time, $s^{*}$, which depends on an innate tendency toward time compression, the objective time frame being assessed, and potentially other characteristics; and an individual discount rate, $d^{*}$, which depends on individual characteristics. Formally,

$$
s_{i}^{*}=Z_{i} \gamma+\eta_{i}
$$

and

$$
d_{i}^{*}=X_{i} \beta+\varepsilon_{i}
$$

Empirically, we observe neither $s^{*}$ nor $d^{*}$. Rather, we observe some individual index of subjective time, $s$ (as based on the millimeters measures), and upper and lower bounds on the latent discount rate, $d^{l}$ and $d^{u}$. As for the latter, ultimately we know that an individual will reveal that their latent discount rate is between the upper and lower bounds according to the probability

$$
\begin{aligned}
& \operatorname{Pr}\left[d_{i}^{l}<d_{i}^{*} \leq d_{i}^{u}\right]=\operatorname{Pr}\left[d_{i}^{l}-X_{i} \beta<\varepsilon_{i} \leq d_{i}^{u}-X_{i} \beta\right] \\
& =\Phi\left(\frac{\exp \left(\frac{\ln F V^{\mathrm{max}}-\ln 100}{s_{i}^{*} /{ }_{365}}\right)-1-X_{i} \beta}{\sigma}\right)-\Phi\left(\frac{\exp \left(\frac{\ln F V^{\min }-\ln 100}{s_{i}^{*} /{ }_{365}}\right)-1-X_{i} \beta}{\sigma}\right)
\end{aligned}
$$

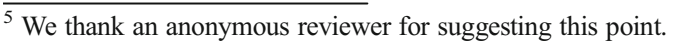


where $\Phi($.$) represents the standard normal CDF; ln 100$ represents the natural log of the $£ 100$ payout that was offered as the immediate payout for each discount choice; FVmin is the future value for the (implicit) row just prior to the respondent switching from preferring the SS to the LL payout; $\mathrm{FV}^{\max }$ is the future value for the (implicit) row where the respondent switches to preferring the LL option; and $\beta$ and $\sigma$ are parameters to be estimated.

One key complication is that to define the upper and lower bounds correctly requires some estimate of $s^{*}$ - the latent number of subjective days the respondent feels when confronted with some specific calendar time (e.g., 1 week). If we define the inverse function of (14) as $f^{-1}(t)$ as the implied number of subjective days associated with every objective time period, $t$, then the log likelihood function for the individual discount rate becomes:

$$
\begin{aligned}
& \ln L= \\
& =\sum_{d_{i}^{*} \in\left[0, a_{i}^{u}\right]} \ln \left(\Phi\left(\frac{\exp \left(\frac{\ln F V^{\max }-\ln 100}{f^{-1\left(z_{i}\right)} /}\right)-1-X_{i 65} \beta}{\sigma}\right)\right) \\
& +\sum_{d_{i}^{*} \in\left[d_{i}^{\prime}, d_{i}^{u}\right]} \ln \left(\Phi\left(\frac{\exp \left(\frac{\ln F V^{\max }-\ln 100}{f^{-1\left(z_{i}\right)} /} /_{365}\right.}{\sigma}\right)-1-X_{i} \beta\right)-\Phi\left(\frac{\exp \left(\frac{\ln F V^{\min }-\ln 100}{f^{-1\left(z_{i}\right)} /}\right)-1-X_{i} \beta}{\sigma 65}\right) \\
& +\sum_{d_{i}^{*} \in\left[d_{i}^{l}, \infty\right]} \ln \left(1-\Phi\left(\frac{\exp \left(\frac{\ln F V^{\min }-\ln 100}{f^{-1\left(z_{i \gamma}\right)} /}\right)-1-X_{i} \beta}{\sigma}\right)\right)
\end{aligned}
$$

We use an iterated maximum likelihood approach to estimating the parameter vector. First, we need an estimate for $f^{-1}(t)$.

Recall that each respondent fills in distances (in $\mathrm{mm}$ ) on a defined line that represents how long they feel each calendar time frame (1 day, 1 week, 4 weeks, 13 weeks, 26 weeks and 52 weeks). Each person uses a distinct frame for this, some using most of the line and some using much less of the line. In order to allow pooling of the observations, we assume that individuals' subjective perception of 1 day is equal to the actual time of 1 day (or, at least approximately so). We then divide the length of the line for each response by the 1-day length for each respondent. This has two benefits. First, it controls for individual heterogeneity in scaling by normalizing the distances for each person's individual scaling behavior. Second, it expresses the distances for each time period in subjective 1-day units. Thus, when we estimate Eq. (14) in terms of normalized lengths, we are estimating the relationship between subjective days and $\mathrm{Z}_{\mathrm{i}}$. 
Additionally, given that our specification included objective days and objective days squared as predictors, once we have the estimated parameters $\widehat{\gamma}$ in hand, then we can generate specific values of $s=f^{-1}(t)$ for all $t$ using a simple quadratic equation. With the estimates of $f^{-1}(t)$ in hand, the upper and lower bounds of the latent discount rates for each time frame for each person were calculated and the primary log likelihood function in Eq. (16) was maximized. Since the discount bounds were based on predictive values for $f^{-1}(t)$, standard errors for the $\beta$ from Eq. (16) were estimated via a bootstrap.

Furthermore, subjects in our experiments could have opted for the same SS option in all pairs in the list, indicating that their implicit discounting rate lay beyond the maximum value of $80 \%$. This upper-bound censoring for those respondents is built into the definition of the likelihood function in Eq. (16) and so is fully accounted for in our model.

Finally, recall that our experimental design broke the Coller and Williams-style payoff table apart for each of our six delay frames and presented each row in a random order. This provided respondents with an opportunity to be "inconsistent" in the sense of switching from Option A (SS) to Option B (LL) in a question and then "switching back" to Option A (SS) in some of the subsequent questions. For those inconsistent responses we have two options. First, we can assume that the lower bound of the latent discount rate is the implied rate for the row before the first switch occurs (if the table was constructed in a proper ascending order) and that the upper bound is the implied rate for the row where the final switch to Option B takes place. In this way, we would preserve each subject's responses, and merely have broader bands on some subjects' implied discount rates. The second option is to just drop the multiple switches. Our empirical analysis has explored both options and results are qualitatively very similar under either approach. The model is more precisely estimated for the second approach, however, and those are the results that we will present here.

\section{Results}

As for the question on "switching back" inconsistency, we found that the vast majority of our subjects were consistent in their responses: only around $11 \%$ of the respondents exhibited multiple switches, that is, switched from Option A to Option B, and then back to Option A (and eventually then back again to Option B). We see this as tentative evidence confirming that the usually high frequencies of consistent choices in incentive-compatible time preferences experiments are not a mere experimental artifact due to the design feature of using an unbroken ascending order of questions within each time horizon block.

The parameter estimates from the prospective subjective time model are presented in Table 1. All the estimations explicitly control for subjects' CRRA as elicited in the risk preferences HL task in the experiment, and for the day of the week of the data collection. In order to avoid forcing the specific Weber-Fechner log-shaped relationship on the data (since that is a primary hypothesis being tested here) we included the delay for the payout and delay squared, rather than the log of delay. We found that the relationship is strongly non-linear in a manner that is consistent with the WeberFechner and Stevens' power laws. Indeed, a version of the model where delay is entered as the natural log performs essentially identically to this specification, both in 
Table 1 Subjective time model

Normalized subjective perception of time

Delay for payout, in days

$0.18 * * *$

(10.00)

Delay for payout, squared

$-0.00025 * * *$

$(-7.08)$

Respondent under-estimates length of experiment

$9.97 * * *$

Respondent is over age 25

$-0.70$

$(-0.25)$

Respondent is female

$(-0.88)$

Respondent is Hindu

4.27

(0.65)

Respondent is Muslim

2.40

Respondent is active in religion

2.69

Respondent has some savings

$-0.12$

$(-0.03)$

Respondent will need savings in coming year

$-0.98$

$(-0.31)$

How satisfied with life overall

Respondent has good or better health

$-0.77$

$(-0.28)$

Respondent's expected years of life

0.049

(0.53)

Ratio of constant relative risk aversion

$-0.0045$

$(-0.39)$

Day is Tuesday

0.89

Day is Wednesday

$-1.52$

$(-0.49)$

Day is Friday

1.83

(0.42)

Constant

$-18.2 *$

$(-1.71)$

Observations

849

$* p<0.10, * * p<0.05, * * * p<0.01$

$\mathrm{T}$-statistics in parentheses 
terms of the statistical significance of logged delay and in terms of $\mathrm{R}^{2}$. We also look at our measure of retrospective time perception based on the perceived duration of the experiment. The mean guess for how long the experiment lasted in total66.1 minutes - was very close to the average actual duration of 61.3 minutes, presumably because responses were anchored to the typical 1-hour duration of a standard experiment in the BRL. While the estimated minutes were thus remarkably accurate on average, $33.7 \%$ of the respondents indeed under-estimated the time.

In addition, subjects who retrospectively under-estimated the length of the experiment in minutes were significantly more likely to have an "expanded" perception of prospective time. Intriguingly, none of the other personal characteristics (including risk aversion), nor the day of the week, significantly affected the perception of prospective time, and did not do so in any of the sensitivity analyses we ran. ${ }^{6}$

In order to generate the predictions of $f^{-1}(t)$ needed to calculate the upper and lower bounds of the discount function, we estimated a limited version of the model in Table 1, with only the delay and delay squared included, then solved for the implied number of subjective days. Fig. 2 plots the average results. Note the similarities to the revealed shape of the subjective days function with the Weber-Fechner and Stevens' power laws hypotheses. Perception of subjective time appears to behave much like perceptions of heat, light and sound, and closely follows a log-shaped curve.

We then estimated two versions of the discount rate model. The first was one where the upper and lower bounds were calculated using objective time as in Eq. (5). The second column in Table 2 are the results from maximizing the log likelihood in Eq. (16) using the upper and lower bounds of the latent discount function taking subjective time into account. In addition to the linear and squared terms for the delay in the payout, we also included an indicator variable for whether the SS date was "today" or "tomorrow" to account for the front end delay and to provide a more precise test of the evolutionary motivation for quasi-hyperbolic preferences: is today versus tomorrow different than today versus any other time frame? Finally, we also include all the variables that were included in our subjective time model, including the individual CRRA and the day of the week.

We found that in both the objective time and subjective time versions of the model the implied discount factor is a function of the delay in the payment, as would be expected. In addition, given the statistically significant parameter of the "SS date is today" variable, there is strong evidence for the hypothesis that the current day discounting differs from discounting in all future periods: like Laury et al. (2012) (but unlike Andersen et al. 2014) we find that implicit discount rates were significantly higher in the individual responses to the questions without FED.

Ultimately, however, we want to know whether accounting for the fact that individuals make choices based on subjective time rather than objective time can explain hyperbolic discounting behavior. To test this, we predicted the implied discount rate for each person in each time frame under both models. The predicted values and the $95 \%$ confidence intervals are presented in Tables 3 and 4, and in Figs. 3 and 4. We find a striking difference between the patterns of predicted discount rates under the two

\footnotetext{
${ }^{6}$ This may be interpreted as evidence consistent with the hypothesis that non-linear subjective time perspective is something determined on a fundamental neuro-physiological level (as in the Weber-Fechner and Stevens' power laws), and not subject to much cultural or environmental modification.
} 


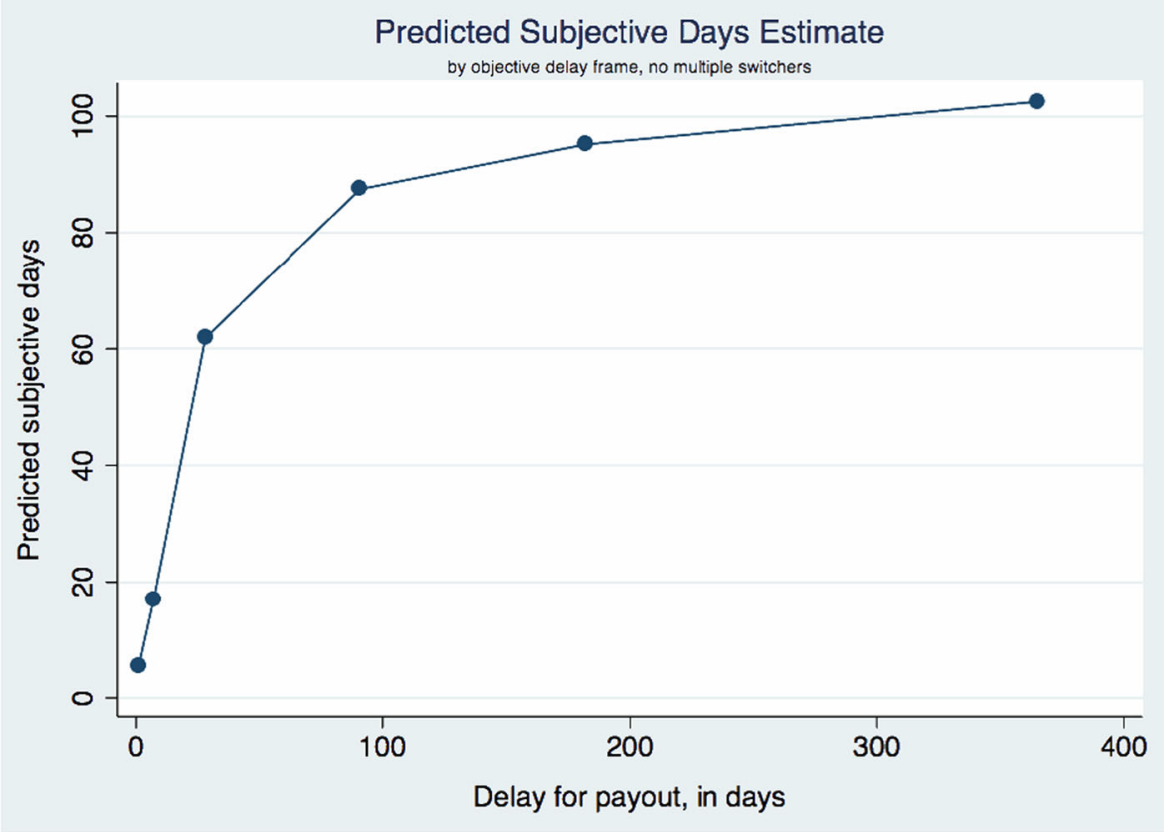

Fig. 2 Estimate of predicted subjective days by objective delay frame

models. When assuming that people respond to objective time, we find discount rates that are high (i.e. above $57 \%$ and up to $110 \%$ per year, consistent with most other estimates of individual discount rates in the literature) and that exhibit a sharply declining rate as the delay increases. This is most easily seen in Fig. 3.

When, however, we account for the non-linearity in each respondent's subjective perception of time, we find predicted discount rates that are: 1) much lower than usually found in the hyperbolic discounting literature, and much more in line with those recently found by Andersen et al. (2014), Andreoni and Sprenger (2012), and Laury et al. (2012) (i.e. in the region of $12-25 \%$ per year) and, ultimately, with market interest rates; 2) higher for "today" compared to all other delays; and 3) statistically indistinguishable from one another for all time delays after today. Much of the hyperbolic pattern evident in Fig. 3 is absent from Fig. 4. It is true that as a point estimate, the discount rate for the 1 -day delay appears higher than for the 1-week through 1-year delays. But, as can be seen in Table 4 and Fig. 4, all the discount rate point estimates for time periods from 1 week to 1 year fall within the $95 \%$ confidence intervals of each other. Thus, like Andersen et al. (2014) and Andreoni and Sprenger (2012) (and, to a large extent, also Laury et al. 2012) we cannot reject the null hypotheses that they are the same.

\section{Discussion and conclusions}

When we assume that subjective time is the same as calendar time, the data from our lab experiment replicate the usual finding of rapidly falling discount 
Table 2 Interval regression model coefficients for discount - No multiple switchers

\begin{tabular}{|c|c|c|}
\hline & Assuming Objective Time & Assuming Subjective Time \\
\hline Delay for payout is today & $\begin{array}{l}0.15^{* * *} \\
(2.61)\end{array}$ & $\begin{array}{l}0.068^{* * * *} \\
(4.53)\end{array}$ \\
\hline Delay for payout, in days & $\begin{array}{l}-0.0026^{* * *} \\
(-4.91)\end{array}$ & \\
\hline Delay for payout, squared & $\begin{array}{l}0.0000040 * * * \\
(3.05)\end{array}$ & \\
\hline Predicted subjective days & & $\begin{array}{l}-0.00085 * * * \\
(-3.83)\end{array}$ \\
\hline Predicted subjective days, squared & & $\begin{array}{l}0.0000023 * * \\
(2.54)\end{array}$ \\
\hline Respondent is over age 25 & $\begin{array}{l}0.0016 \\
(0.04)\end{array}$ & $\begin{array}{l}0.0060 \\
(0.62)\end{array}$ \\
\hline Respondent is female & $\begin{array}{l}-0.060 * \\
(-1.76)\end{array}$ & $\begin{array}{l}0.018 \\
(1.64)\end{array}$ \\
\hline Respondent is Hindu & $\begin{array}{l}0.044 \\
(0.77)\end{array}$ & $\begin{array}{l}-0.012 \\
(-0.90)\end{array}$ \\
\hline Respondent is Muslim & $\begin{array}{l}0.061 \\
(1.05)\end{array}$ & $\begin{array}{l}0.036^{*} \\
(1.83)\end{array}$ \\
\hline Respondent is active in religion & $\begin{array}{l}0.035 \\
(0.84)\end{array}$ & $\begin{array}{l}-0.025^{* *} \\
(-1.97)\end{array}$ \\
\hline Respondent has some savings & $\begin{array}{l}-0.14 * * * \\
(-3.55)\end{array}$ & $\begin{array}{l}-0.013 \\
(-1.16)\end{array}$ \\
\hline Respondent will need savings in coming year & $\begin{array}{l}0.031 \\
(0.85)\end{array}$ & $\begin{array}{l}0.028^{* * * *} \\
(2.58)\end{array}$ \\
\hline How satisfied with life overall & $\begin{array}{l}-0.019 \\
(-1.58)\end{array}$ & $\begin{array}{l}0.000025 \\
(0.01)\end{array}$ \\
\hline Respondent has good or better health & $\begin{array}{l}0.069^{*} \\
(1.87)\end{array}$ & $\begin{array}{l}0.0065 \\
(0.68)\end{array}$ \\
\hline Respondent's expected years of life & $\begin{array}{l}0.0032^{* *} \\
(2.16)\end{array}$ & $\begin{array}{l}-0.00047 \\
(-1.00)\end{array}$ \\
\hline Ratio of constant relative risk aversion & $\begin{array}{l}0.000025 \\
(0.18)\end{array}$ & $\begin{array}{l}-0.000019 \\
(-0.51)\end{array}$ \\
\hline Constant & $\begin{array}{l}0.91 * * * \\
(6.02)\end{array}$ & $\begin{array}{l}0.19 * * * \\
(4.03)\end{array}$ \\
\hline \multicolumn{3}{|l|}{ lnsigma } \\
\hline Constant & $\begin{array}{l}-0.88 * * * \\
(-22.27)\end{array}$ & $\begin{array}{l}-2.41 * * * \\
(-38.71)\end{array}$ \\
\hline Observations & 855 & 727 \\
\hline
\end{tabular}

$* p<0.10, * * p<0.05, * * * p<0.01$

T-statistics in parentheses 
Table 3 Predicted discount rate assuming objective time, no multiple switchers

\begin{tabular}{llll}
\hline & $(1)$ & $(2)$ & $(3)$ \\
\hline & $95 \%$ CI Lower Bound & Predicted Discount Rate & $95 \%$ CI Upper Bound \\
& Mean & Mean & Mean \\
1 & 0.971 & 1.113 & 1.256 \\
7 & 0.830 & 0.953 & 1.075 \\
28 & 0.784 & 0.900 & 1.016 \\
91 & 0.653 & 0.767 & 0.881 \\
182 & 0.510 & 0.630 & 0.749 \\
365 & 0.440 & 0.564 & 0.689 \\
Observations & 855 & 855 & 855 \\
\hline
\end{tabular}

rates with increasing delays. Our data, however, reject the equivalence between subjective and calendar time. When we adjust for the difference between calendar delay and perceived delay, we find very different patterns of discount rates: while discounting based on "objective time" replicates the usual hyperbolic function, the curve of discount rates obtained from "subjective time" does not exhibit much of the hyperbolic pattern, and resembles the shape of a quasihyperbolic function. Accounting for individual perception of time thus drives a wedge between time discounting and "pure" time preferences. We find that there remains a "first day" effect of delay on time preferences-where respondents appear to have genuinely higher impatience when choosing between today and tomorrow, or today and any further point in the future-but that discount rates for delays from 1 week to 1 year are statistically indistinguishable. Thus, considering direct measures of subjectively perceived time instead of objective time can lead to different conclusions on the estimated discount rates even when these are elicited through experimental tests with real monetary rewards.

Our results replicate and qualify the main findings by Zauberman et al. (2009) using incentive-compatible measures for time preferences. Like in Zauberman et al. (2009) within-subjects experiment 2 , in fact, our estimations also reject hyperbolic discounting

Table 4 Predicted discount rate assuming subjective time, no multiple switchers

\begin{tabular}{llll}
\hline & $(1)$ & $(2)$ & $(3)$ \\
\hline & $95 \%$ CI Lower Bound & Predicted Discount Rate & $95 \%$ CI Upper Bound \\
& Mean & Mean & Mean \\
1 & 0.194 & 0.229 & 0.264 \\
7 & 0.115 & 0.152 & 0.189 \\
28 & 0.0958 & 0.133 & 0.171 \\
91 & 0.0851 & 0.123 & 0.160 \\
182 & 0.0844 & 0.122 & 0.160 \\
365 & 0.0823 & 0.121 & 0.160 \\
Observations & 727 & 727 & 727 \\
\hline
\end{tabular}




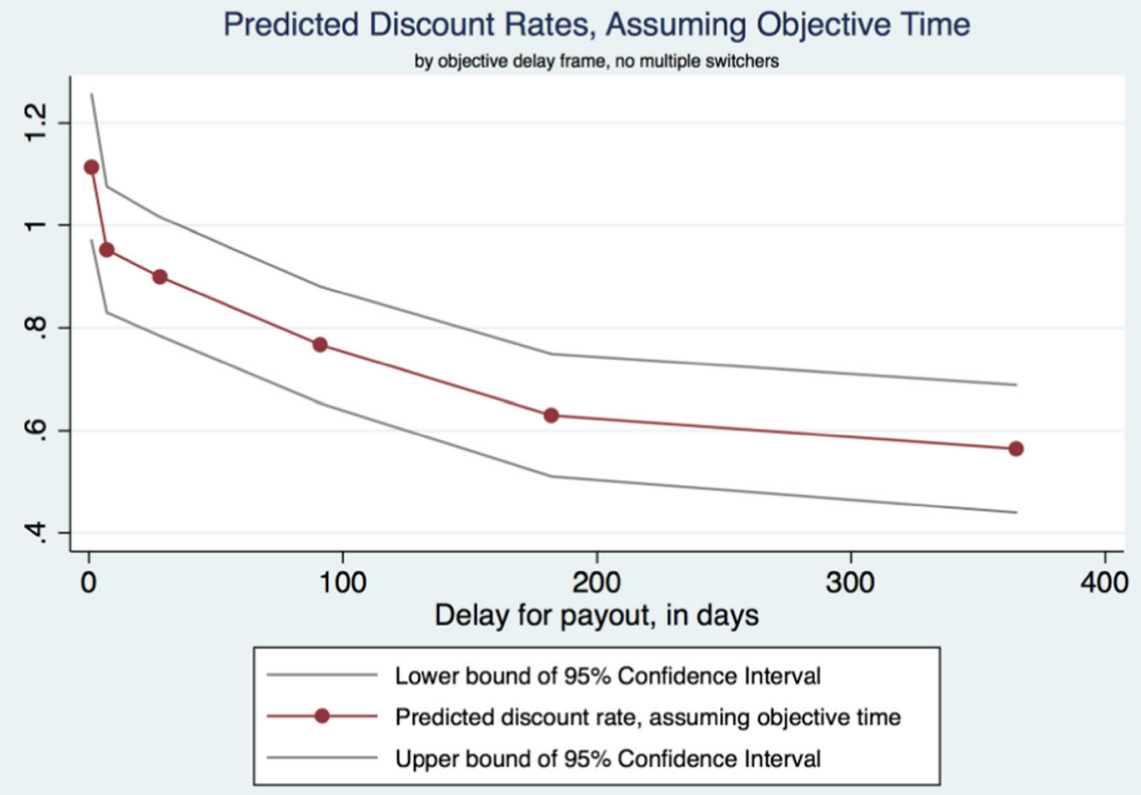

Fig. 3 Predicted discount rates, assuming objective time

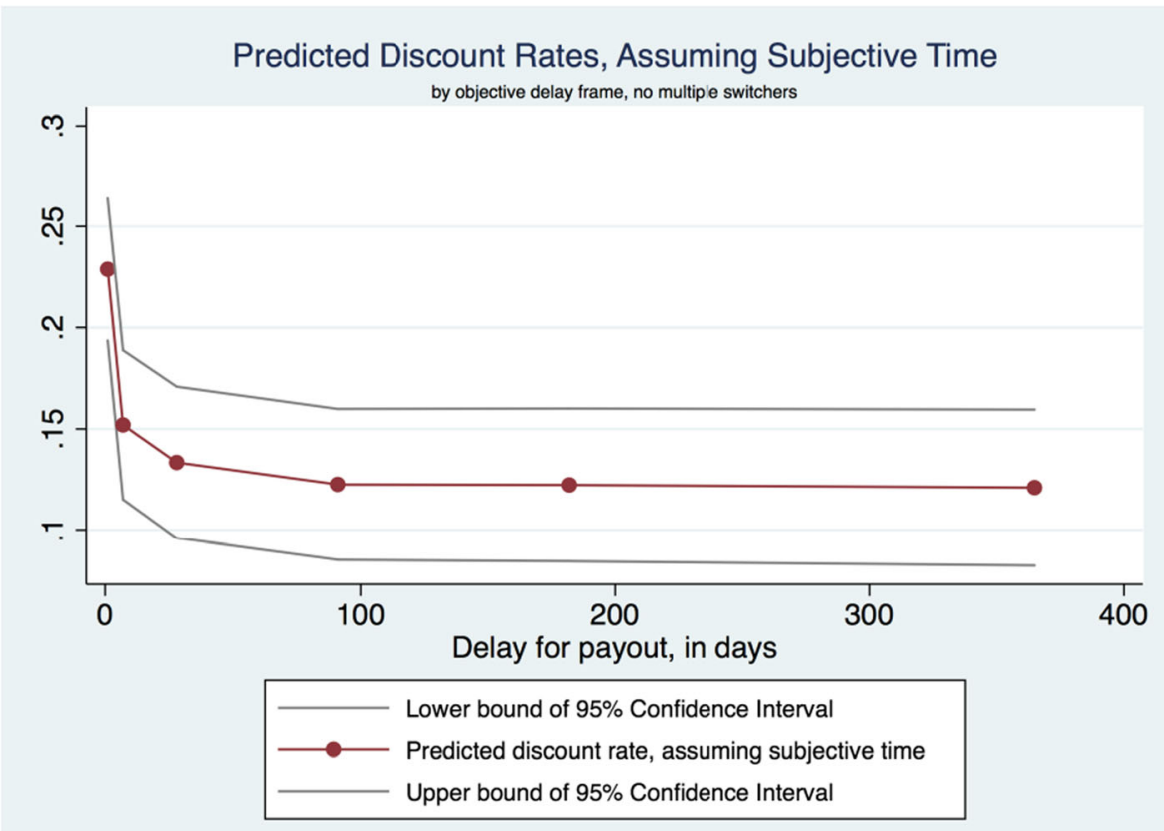

Fig. 4 Predicted discount rates, assuming subjective time 
when discounting rates are fitted using subjective time. The convergence in findings is noteworthy because, as explained, we elicit time discounting using experimental tests with real monetary rewards, and we rescale the individual responses for the time perception of horizons beyond 1 day using the same subject perception of 1 day. To the best of our knowledge, this is the first time that the findings by Zauberman et al. (2009) have been replicated using incentive-compatible measures of time discounting. Our results also qualify the main findings by Zauberman et al. (2009) because we document a "first day" effect on time discounting when this is calculated with subjective time. We are able to capture this "quasi-hyperbolic" shape of time discounting because we consider time horizons of 1 day, 1 week, 4, 13, 26, and 52 weeks, while the shortest time horizon in Zauberman et al. (2009) is 3 months.

Our results can be related to the findings by Anderhub et al. (2001), Harrison et al. (2002), Andersen et al. (2008, 2014), Read (2001) and Andreoni and Sprenger (2012) who also find no significant evidence of hyperbolic discounting in most of their empirical specifications, and to the recent findings by Attema et al. $(2016,2018)$ who find mixed evidence of decreasing impatience when discounting is measured directly without measuring utility. ${ }^{7}$ Our results are also generally in line with Laury et al. (2012) who find that, if the soonest payment date was at least 2 weeks in the future, constant discounting could not be rejected.

Our study has several limitations. First, in order to directly compare the discounting functions calculated with objective and subjective time, we employ an estimation approach based on interval regression instead of a full information maximum likelihood (FIML) approach like the one developed by Andersen et al. $(2008,2014)$ for the structural estimation of different discounting models. Second, and relatedly, we only focus on the estimation of time preferences, while controlling for risk aversion, instead of jointly estimating risk and time preferences together (Ferecatu and Onçuler 2016). Andersen et al. $(2008,2014)$ show that is impossible to infer the level of the respondents' discount rates without knowing or assuming something about their risk attitudes, and that the structural joint estimations of risk and time preferences lead to estimated levels of the discount rates that are substantially lower than what would be found by estimating time preferences alone. It is thus possible that some, or most, of the hyperbolic curvature of the discounting function that we find using objective time would disappear if risk and time preferences would be structurally estimated jointly. ${ }^{8}$ Third, and again relatedly, our design does not allow us to directly measure and control for the curvature of utility for risk and time as done in Abdellaoui et al. (2013), Cheung (2015b), and Epper and Fehr-Duda (2015). Addressing each of these questions would

\footnotetext{
${ }^{7}$ An exception is the Read-Weibull specification in Andersen et al. (2014), which, as noted, is conceptually analogous to the idea of adjusting the discounting function for individual time perception: in that case, discount rates were found to be slightly decreasing, although the hypothesis of exponential discounting could not be rejected. Our findings differ from Andersen et al. (2014) mainly in that, even after correcting for subjective time perception, we find a significantly higher discounting for the very "first day". This result could be due to differences in the studies' design (e.g. they use 2 weeks as a shortest time horizon, together with a 1month FED, while we directly include 1-day time horizons), or by obvious differences in the students-adults, or the UK-Denmark, subjects pools.

${ }^{8}$ This is even more the case if the structural estimations of risk preferences allow us to also consider non-EUT models, such as the Rank-Dependent Utility model by Quiggin (1982), which explicitly accounts for subjective probability weighting. Epper et al. (2011), in fact, find that hyperbolic discounting is significantly associated with non-linear weighting in the subjective perception of probabilities ("sub-proportionality").
} 
require a different design and/or a more structural econometric approach, and we leave to further research the intriguing questions of whether the Weber-Fechner-shaped curvature of the individual perception of time may be related to the curvature of utility for risk and time, to non-linear probability weighting, and to decreasing impatience and other forms of non-stationary time preferences in the sense of Prelec (2004) and Bleichrodt et al. (2009). A further clear limitation of our study is that it considers a specific sample of university students, and we envisage further replications with more representative samples of the population (Bradford et al. 2017; Galizzi et al. 2019).

In future work, we envision being able to directly investigate how to measure subjective perception of time using real incentives and different experimental designs (e.g. shorter periods of time, alternative methods to measure discounting). Other questions which deserve explicit investigation are whether discounting functions adjusted for subjective time are associated with other selfreported measures commonly used in surveys, such as impulsiveness (Patton and Stanford 1995), self-control (Tangney et al. 2004), and financial planning horizon (Petry et al. 1998); other specific constituent motives of time discounting, such as impulsivity, compulsivity, and inhibition (in the sense of Frederick et al. 2002); age, numeracy, and cognitive skills, which have already been documented to correlate with time preferences (Dohmen et al. 2008; Burks et al. 2009; Andersson et al. 2016); and whether or not they are stable across different domains (Ioannou and Sadeh 2016).

Notwithstanding these limitations, if confirmed, our findings may be of significant practical importance. Policy interventions designed on the assumption that, in our inter-temporal decisions, we are affected by hyperbolic discounting - such as the ones involving commitment devices, front-end monetary incentives, and pre-commitment defaults - can fruitfully explore future behavioral manipulations that make more salient and vivid the objective time windows of our choices, in the attempt to overcome, or at least compensate for, our tendency to subjectively compress time.

Acknowledgements We gratefully thank for discussion, comments, and suggestions the Editor-in-Chief, Kip Viscusi, the Editorial Board, and an anonymous reviewer; Han Bleichrodt, Pablo Brañas-Garza, Wandi Bruine De Bruin, Enrica Carbone, Stephen Cheung, Anna Conte, Robin Cubitt, Daniela Di Cagno, Luca Di Corato, Randall P. Ellis, Helga Fehr-Duda, Glenn Harrison, John Hey, Andre Hofmeyr, Heather Kappes, Peter Katuscak, Laura Kudrna, Graham Loomes, Natalia Montinari, Luca Panaccione, Marco Piovesan, Drazen Prelec, Daniel Read, Kirsten Rohde, Tobias Schmidt, Charles Sprenger, Gianandrea Staffiero, Barbara Summers, Severine Toussaert, Erik Wengstrom; and all the participants at the ESA World Meetings in Zurich; the ASHEcon Conference in Minneapolis; and the NIBS Conference in Nottingham; and to seminars at City University London, Leeds University Business School, LSE, LUISS, Lund, Middlesex University London. We gratefully acknowledge funding from the ESRC (Future Research Leader Grant ES/K001965/1, PI: Matteo M Galizzi). We are grateful to Christina Stoddard for her constant support and for the excellent proofreading of the article. We gratefully thank Barbara Fasolo and Jamie Moss for their generous support in accessing the LSE Behavioural Research Lab (BRL) and its mailing list. Excellent research assistance by Maria De Francesco and Enrico Regiroli is gratefully acknowledged.

Open Access This article is distributed under the terms of the Creative Commons Attribution 4.0 International License (http://creativecommons.org/licenses/by/4.0/), which permits unrestricted use, distribution, and reproduction in any medium, provided you give appropriate credit to the original author(s) and the source, provide a link to the Creative Commons license, and indicate if changes were made. 


\section{References}

Abdellaoui, M., Bleichrodt, H., l'Haridon, O., \& Paraschiv, C. (2013). Is there one unifying concept of utility? An experimental comparison of utility under risk and utility over time. Management Science, 59(9), 2153-2169.

Ainslie, G. (1975). Specious reward: A behavioral theory of impulsiveness and impulse control. Psychological Bulletin, 82(4), 463-496.

Ainslie, G. (1991). Derivation of "rational" economic behavior from hyperbolic discount curves. The American Economic Review, 81(2), 334-340.

Anderhub, V., Güth, W., Gneezy, U., \& Sonsino, D. (2001). On the interaction of risk and time preferences: An experimental study. German Economic Review, 2(3), 239-253.

Andersen, S., Harrison, G. W., Lau, M. I., \& Rutström, E. E. (2008). Eliciting risk and time preferences. Econometrica, 76(3), 583-618.

Andersen, S., Harrison, G. W., Lau, M. I., \& Rutström, E. E. (2014). Discounting behavior: A reconsideration. European Economic Review, 71, 15-33.

Andersson, O., Holm, J.H., Tyran, J.R., \& Wengstrom, E. (2016). Risk aversion relates to cognitive ability: preferences or noise? Journal of the European Economic Association, 14(5), 1129-1154.

Andreoni, J., \& Sprenger, C. (2012). Risk preferences are not time preferences. The American Economic Review, 102(7), 3357-3376.

Andreoni, J., Kuhn, M. A., \& Sprenger, C. (2015). Measuring time preferences: A comparison of experimental methods. Journal of Economic Behavior and Organization, 116, 451-464.

Angerer, S., Lergetporer, P., Glatzle-Rutzler, D., \& Sutter, M. (2015). How to measure time preferences in children: A comparison of two methods. Journal of the Economic Science Association, 1(2), 158-169.

Attema, A. E., Bleichrodt, H., \& Wakker, P. P. (2012). A direct method for measuring discounting and QALYs more easily and reliably. Medical Decision Making, 32(4), 583-593.

Attema, A. E., Bleichrodt, H., Gao, Y., Huang, Z., \& Wakker, P. P. (2016). Measuring discounting without measuring utility. American Economic Review, 106(6), 1476-1494.

Attema, A. E., Bleichrodt, H., l'Haridon, O., Peretti-Watel, P., \& Seror, V. (2018). Discounting health and money: New evidence using a more robust method. Journal of Risk and Uncertainty, 56(2), 117-140.

Barsky, R. B., Juster, F. T., Kimball, M. S., \& Shapiro, M. D. (1997). Preference parameters and behavioral heterogeneity: An experimental approach in the Health and Retirement Study. The Quarterly Journal of Economics, 112(2), 537-579.

Bleichrodt, H., Rohde, K. I. M., \& Wakker, P. P. (2009). Non-hyperbolic time inconsistency. Games and Economic Behavior, 66(1), 27-38.

Bradford, W. D. (2010). The association between individual time preferences and health maintenance habits. Medical Decision Making, 30(1), 99-112.

Bradford, W. D., Courtemanche, C., Heutel, G., McAlvanah, P., \& Ruhm, C. (2017). Time preferences and consumer behavior. Journal of Risk and Uncertainty, 55(3), 119-145.

Burks, S. V., Carpenter, J. P., Goette, L., \& Rustichini, A. (2009). Cognitive skills affect economic preferences, strategic behavior, and job attachment. Proceedings of the National Academy of Sciences, 106(19), 7745-7750.

Chabris, C. F., Laibson, D., Morris, C. L., Schuldt, J. P., \& Taubinsky, D. (2008). Individual laboratorymeasured discount rates predict field behavior. Journal of Risk and Uncertainty, 37(2-3), 237-269.

Chapman, G. B., \& Coups, E. J. (1999). Time preferences and preventive health behavior: Acceptance of the influenza vaccine. Medical Decision Making, 19(3), 307-314.

Chesson, H. W., \& Viscusi, W. K. (2000). The heterogeneity of time-risk tradeoffs. Journal of Behavioral Decision-Making, 13(2), 251-258.

Cheung, S. L. (2015a). Comment on "Risk preferences are not time preferences": On the elicitation of time preference under conditions of risk. The American Economic Review, 105(7), 2242-2260.

Cheung, S. L. (2015b). Eliciting utility curvature and time preference. University of Sydney working paper 2015-1.

Cheung, S. L. (2016). Recent developments in the experimental elicitation of time preference. IZA Discussion Paper 9898.

Coble, K. H., \& Lusk, J. L. (2010). At the nexus of risk and time preferences: An experimental investigation. Journal of Risk and Uncertainty, 41(1), 67-79.

Coller, M., \& Williams, M. (1999). Eliciting individual discount rates. Experimental Economics, 2(2), 107-127.

Coller, M., Harrison, G. W., \& Rutström, E. E. (2012). Latent process heterogeneity in discounting behavior. Oxford Economic Papers, 64(2), 375-391. 
Cubitt, R. P., \& Read, D. (2007). Can intertemporal choice experiments elicit time preferences for consumption? Experimental Economics, 10(4), 369-389.

Dehaene, S. (2003). The neural basis of the Weber-Fechner law: A logarithmic mental number line. Trends in Cognitive Sciences, 7(4), 145-147.

Dohmen, T. J., Falk, A., Huffman, D., \& Sunde, U. (2008). Are risk aversion and impatience related to cognitive ability? American Economic Review, 100(3), 1238-1260.

Dolan, P., \& Gudex, C. (1995). Time preference, duration, and health state valuations. Health Economics, 4(4), 289-299.

Ebert, J. E., \& Prelec, D. (2007). The fragility of time: Time-insensitivity and valuation of the near and far future. Management Science, 53(9), 1423-1438.

Epper, T., \& Fehr-Duda, H. (2015). Risk preferences are not time preferences: Balancing on a budget line: Comment. American Economic Review, 105(7), 2261-2271.

Epper, T., Fehr-Duda, H., \& Bruhin, A. (2011). Viewing the future through a warped lens: Why uncertainty generates hyperbolic discounting. Journal of Risk and Uncertainty, 43(3), 169-203.

Ferecatu, A., \& Onçuler, A. (2016). Heterogeneous risk and time preferences. Journal of Risk and Uncertainty, 53(1), 1-28.

Frederick, S., Loewenstein, G., \& O’Donoghue, T. (2002). Time discounting and time preference: A critical review. Journal of Economic Literature, 40(2), 351-401.

Galizzi, M. M., Harrison, G. W., \& Miniaci, R. (2019). Linking experimental and survey data for a UK representative sample: Structural estimation of risk and time preferences. Unpublished manuscript, London School of Economics.

Harrison, G. W., Lau, M. I., \& Williams, M. B. (2002). Estimating individual discount rates in Denmark: A field experiment. The American Economic Review, 92(5), 1606-1617.

Holden, S. T., \& Quiggin, J. (2017). Bounded awareness and anomalies in intertemporal choice: Zooming in Google Earth as both metaphor and model. Journal of Risk and Uncertainty, 54(1), 15-35.

Holt, C. A., \& Laury, S. K. (2002). Risk aversion and incentive effects. American Economic Review, 92(5), $1644-1655$.

Hornik, J. (1984). Subjective vs. objective time measures: A note on the perception of time in consumer behavior. Journal of Consumer Research, 11(1), 615-618.

Ioannou, C. A., \& Sadeh, J. (2016). Time preferences and risk aversion: Tests on domain differences. Journal of Risk and Uncertainty, 53(1), 29-54.

Jamison, D. T., \& Jamison, J. (2011). Characterizing the amount and speed of discounting procedures. Journal of Benefit-Cost Analysis, 2(2), 1-56.

Kim, B. K., \& Zauberman, G. (2009). Perception of anticipatory time in temporal discounting. Journal of Neuroscience, Psychology, and Economics, 2(2), 91-101.

Kirby, K. N., \& Marakovic, N. (1995). Modeling myopic decisions: Evidence for hyperbolic and delaydiscounting within subjects and amounts. Organizational Behavior and Human Decision Processes, 64(1), 22-30.

Kirby, K. N., Petry, N. M., \& Bickel, W. K. (1999). Heroin addicts have higher discount rates for delayed rewards than non-drug-using controls. Journal of Experimental Psychology: General, 128(1), 78-87.

Laibson, D. (1997). Golden eggs and hyperbolic discounting. The Quarterly Journal of Economics, 112(2), 443-478.

Laury, S. K., McInnes, M. M., \& Swarthout, J. T. (2012). Avoiding the curves: Direct elicitation of time preferences. Journal of Risk and Uncertainty, 44(3), 181-217.

Loewenstein, G. (1996). Out of control: Visceral influences on behavior. Organizational Behavior and Human Decision Processes, 65(3), 272-292.

Loewenstein, G., \& Prelec, D. (1992). Anomalies in intertemporal choice: Evidence and an interpretation. The Quarterly Journal of Economics, 107(2), 573-597.

Patton, J. H., \& Stanford, M. S. (1995). Factor structure of the Barratt impulsiveness scale. Journal of Clinical Psychology, 51(6), 768-774.

Petry, N. M., Bickel, W. K., \& Arnett, M. (1998). Shortened time horizons and insensitivity to future consequences in heroin addicts. Addiction, 93(5), 729-738.

Phelps, E. S., \& Pollak, R. A. (1968). On second-best national saving and game-equilibrium growth. The Review of Economic Studies, 35(2), 185-199.

Prelec, D. (2004). Decreasing impatience: A criterion for non-stationary time preference and "hyperbolic" discounting. The Scandinavian Journal of Economics, 106(3), 511-532.

Prelec, D., \& Loewenstein, G. (1991). Decision making over time and under uncertainty: A common approach. Management Science, 37(7), 770-786.

Read, D. (2001). Is time-discounting hyperbolic or subadditive? Journal of Risk and Uncertainty, 23(1), 5-32. 
Roelofsma, P. H. (1996). Modelling intertemporal choices: An anomaly approach. Acta Psychologica, 93(1), $5-22$.

Samuelson, P. (1947). Foundations of economic analysis. Cambridge: Harvard University Press.

Scholten, M., \& Read, D. (2006). Discounting by intervals: A generalized model of intertemporal choice. Management Science, 52(9), 1424-1436.

Stevens, S. S. (1957). On the psychophysical law. Psychological Review, 64(3), 153-181.

Strotz, R. H. (1955). Myopia and inconsistency in dynamic utility maximization. The Review of Economic Studies, 23(3), 165-180.

Sutter, M., Kocher, M. G., Glätzle-Rützler, D., \& Trautmann, S. (2013). Impatience and uncertainty: Experimental decisions predict adolescents' field behavior. American Economic Review, 103(1), 510-531.

Takeuchi, K. (2011). Non-parametric test of time consistency: Present bias and future bias. Games and Economic Behavior, 71(2), 456-478.

Tangney, J. P., Baumeister, R. F., \& Boone, A. L. (2004). High self-control predicts good adjustment, less pathology, better grades, and interpersonal success. Journal of Personality, 72(2), 271-324.

Thaler, R. (1981). Some empirical evidence on dynamic inconsistency. Economics Letters, 8(3), 201-207.

Trope, Y., \& Liberman, N. (2003). Construal-level theory of psychological distance. Psychological Review, $117(2), 440-463$.

Van der Pol, M., \& Cairns, J.A. (2001). Estimating time preferences for health using discrete choice experiments. Social Science and Medicine, 52, 1459-1470.

Weber, E. H. (1978). The sense of touch. H. E. Ross, Trans. (Original work published 1834). London: Academic Press for Experimental Psychology Society.

Wittmann, M., \& Paulus, M. P. (2008). Decision making, impulsivity and time perception. Trends in Cognitive Sciences, 12(1), 7-12.

Zauberman, G., Kim, B. K., Malkoc, S. A., \& Bettman, J. R. (2009). Discounting time and time discounting: Subjective time perception and intertemporal preferences. Journal of Marketing Research, 46(4), 543-556.

Publisher's note Springer Nature remains neutral with regard to jurisdictional claims in published maps and institutional affiliations.

\section{Affiliations}

\section{W. David Bradford ${ }^{1} \cdot$ Paul Dolan $^{2} \cdot$ Matteo M. Galizzi ${ }^{3}$}

1 Department of Public Administration and Policy, and Department of Economics, University of Georgia, 201C Baldwin Hall, Athens, GA 30602, USA

2 Department of Psychological and Behavioural Science, London School of Economics, 3.08 Queens House, 55/56 Lincoln's Inn Fields, WC2A3LJ, London, UK

3 London School of Economics, Department of Psychological and Behavioural Science, and LSE Behavioural Science Hub, 3.16 Queens House, 55/56 Lincoln's Inn Fields, WC2A3LJ, London, UK 